\title{
Beyond economic growth
}

\section{The future of the Environmentally sustainable national income}

\author{
Our planet is threatened by a wrong belief in \\ a wrongly formulated growth. Estimating the \\ distance between gross domestic product and \\ environmentally sustainable national income \\ can greatly improve the information about \\ economic growth. \\ By Roefie Hueting
}

\begin{abstract}
A 1 economic action is directed to the satisfaction of wants, or in other words: to welfare. Welfare is defined as the satisfaction of wants derived from our dealings with scarce goods. It is a category of personal experience and not measurable in cardinal units. Therefore we have to do it with indicators that are measurable in cardinal units and that are arguably influencing welfare. The cardinal indicator and the ordinal welfare have, of course, to develop in the same direction.

Economic growth is generally defined as increase of national income (NI) or Gross domestic product (GDP) as a measure of production. However, according to the subject matter of economics, economic growth can mean nothing other than increase in welfare. Welfare is dependent on more factors than solely production. It is also dependent on employment, income distribution, labour conditions, leisure time and the scarce possible uses of the non-human-made physical surroundings: the environmental functions. These objectives or ends are often conflicting. Therefore welfare can increase with decreasing production.

The narrow minded, theoretically wrong definition of economic growth is especially threatening the current and future availability of environmental functions, the most fundamental scarce and consequently economic goods at the disposal of humanity. Below it is elucidated why this is the case and some relatively simple ways are discussed to counteract the fatal effect of this wrong definition on the environment.
\end{abstract}

\section{Environmental functions}

For an economic approach the environment can best be defined as the non-human-made physical surroundings, or elements thereof, on which humanity is entirely dependent in all its doings, whether they be producing, consuming, breathing or recreating. These physical surroundings encompass water, air, soil, natural resources, including energy resources, plant and animal species and the life support systems, including ecosystems, of our planet. Our physical surrounding has a great number of possible uses. These are called environmental functions or in short: functions. Examples are gene pool, habitat for biological species, water as raw material for drinking water, air for the physiological functioning of humans, animals and plants, soil for cultivating crops and the many functions of non-renewable natural resources (Hueting 1974/1980).

These functions and systems have come into being largely via processes proceeding at a geological or evolutionary pace. For the life support systems it is unfeasible ever completely to be replaced by technology as is shown by Goodland (Goodland 1995). It is thanks to these life support systems, which are under threat of disruption, that indispensable environmental functions remain available.

Life support systems are understood to mean the processes that maintain the conditions necessary for life on earth. This comes down to maintaining equilibria within narrow margins. The processes may be of a biological or physico-chemical nature, or a combination thereof. Examples of biological processes include the carbon and nutrient cycles, involving the extraction of such substances as carbon dioxide, water and minerals from the abiotic environment during creation of biomass, and the return of these substances to the abiotic environment during decomposition of the biomass. Examples of physicochemical processes include the water cycle and regulation of the thickness of the stratospheric ozone layer. These examples show that there is interaction between the processes, whereby equilibrium may be disturbed. The water cycle, for example, may be disturbed by large-scale deforestation. Climate change is a disturbance of the carbon cycle, leading to melting of the glaciers.

As long as the use of a function does not hamper the use of another or the same function, so as long as environmental functions are not scarce, an insufficiency of labour, that is intellect or technology, is the sole factor limiting production growth, as measured in standard NI. As soon as one use of a function is at the expense of another or the same function by excessive use, though, or threatens to be so in the future, a second limiting factor is introduced. As an illustration, once certain water pollutant thresholds have been exceeded, use of the function „dumping ground for waste" may come to compete with the function "drinking water". An example of excessive use of one and the same function „water to accommodate the habitat for fish species or ecosystems", leading to its loss, is overfishing resulting in decreased availability of the function; then the catch of 
some species decreases or species become extinct. Many species and ecosystems of which they were a part, in other words many functions, have indeed already been lost. The function „soil for cultivating crops" may be damaged by unsustainable use of the function "supplier of timber" of a forest, leading to loss of its function "regulator of the water flow" and subsequent erosion; it may also be in conflict with itself, when unsustainable farming methods lead to erosion and salinization of the soil. The many functions of natural resources that threaten to get lost as a result of exhaustion of the resource are in competition with themselves. This competition of functions leads to partial or complete loss of function.

Competing functions are by definition economic goods. For, when functions compete an alternative will always have to be sacrificed, which is described by the term opportunity costs. By defining our physical surroundings as a collection competing functions, the environment, and environmental losses, acquires a central place in economic theory, in contrast to an approach whereby these losses are viewed as external effects.

Three categories of competition between functions are distinguished: spatial, quantitative and qualitative.

Spatial competition occurs when the amount of space is inadequate to satisfy existing wants, or threatens to be so in the future. Worldwide severe competition exists between use of space for production of food, production of bio fuels, natural ecosystems and the survival of species, road building, building of houses, traffic and possibilities for children to discover their surroundings. Especially the function "space for the existence of natural ecosystems" is threatened. Spatial competition is probably the main cause of species extinction, through loss and fragmentation of habitats. Everything points to this process continuing unless drastic measures are taken.

In the case of quantitative competition, it is the amount of matter that is deficient or threatens to be so in the future. We are here concerned with natural resources such as oil, copper and groundwater, which are exhaustible and non-renewable on a human time scale or which cannot increase in quantity, such as water. In many regions of the world the quantity of ground and surface water is insufficient to meet the needs for both raining on agricultural crops and industrial processes and drinking water and the survival of species.

With qualitative competition, it is always one and the same function, the function "waste dumping medium", or much more accurately: „addition or withdrawal of species and matter” that is in conflict with other possible uses such as "drinking water“, „physiological functioning of humans, plants and animals " and „habitat for species“. The introduction of agents into water, soil and air or their withdrawal from them, in the course of a given activity, alters the quality of these environmental media, and as a result, other uses of them may be disturbed or rendered impossible. Agents may be chemical substances, plants, animals, heat, ionizing radiation and so on. Qualitative competition includes pollution, disturbance of ecosystem by exotics and phenomena such as climate change.
When using the concept of function, the only thing that matters in the context of environmental sustainability is that vital functions remain available. As for renewable resources, functions remain available as long as their regenerative capacity remains intact. Regeneration in relation to current use of non-renewable resources such as crude oil and copper that are formed by slow geological processes is close to zero. Regeneration then takes the form of developing substitutes. The possibilities for this are hopeful (Reijnders 1996). Therefore, economically speaking, there seems to be no essential difference between the two.

Competition between functions is a manifestation of the finite nature of the environment, and to trace this competition in appropriate matrices is to expose the underlying conflicts. This has been done by Hueting (1974/1980). The conflict proves to lie almost entirely in the use of environmental functions for production and consumption, and growth thereof, in the here and now, at the expense of other desired uses and of future availability of environmental functions, including those functions necessary for production and consumption. In other words, the conflict boils down essentially to a question of sustainable versus unsustainable use of environmental functions. Environmental sustainability requires safeguarding vital environmental functions for future generations. In an environmentally sustainable situation, essential functions are kept available from generation to generation.

\section{Valuation: a practical solution for an unsolvable problem}

When functions become scarce, their value rises from zero, that is abundant available with respect to existing wants to an ever-rising positive value. This rise in value reflects a rise in costs. The higher the value, the greater the impoverishment. To determine the extent of the loss of function, we must know the value of the function. Since environmental functions are collective goods that are not traded on the market, supply and demand curves have to be constructed. Without data on both preferences (demand) and opportunity costs (supply), determination of value is impossible.

The estimated costs of measures necessary to restore functions, that rise progressively per unit of function restored, can be seen as a supply curve, because it supplies the function. We call this the cost-effectiveness curve or the elimination cost curve, because it refers to measures that eliminate the pressure on the environment. Except in the case of irreparable damage, the elimination costs can always be estimated, so this curve can always be constructed. The measures include technical measures, direct shifts to environmentally benign production and consumption, development of alternatives for depletable resources such as oil and cupper, and family planning.

Preferences for environmental functions (demand), on the contrary, can only partially be determined, since the possibilities for preferences for the current and future use of envi- $\rightarrow$ 
ronmental functions to manifest themselves in market behaviour are very limited (Hueting 1974/1980). Consequently, it is not possible to construct a complete demand curve. Expenditure on compensation for loss of function and on restoration of physical damage resulting from loss of function, however, constitute revealed preferences for the availability of functions, so that some impression of these preferences can be obtained. One example is the restoration of damage caused by flooding due to excessively cutting forests, thus overusing the function „provider of wood“, as a result of which forests are losing their function „regulation of the water flow“.

Efforts have been made to trace these preferences by asking people how much they would be prepared to pay to wholly or partially restore lost environmental functions and to conserve them. Much research is being done on willingness to pay or to accept (contingent valuation). However, this method does mostly not provide reliable estimates for many reasons, especially not for vital functions (Hueting 1989).

Consequently, the shadow prices of environmental functions remain unknown. This means that the correct prices of human made goods that are produced and consumed at the expense of environmental functions, and on which the national income should be based, remain equally unknowable. However, to provide the necessary information, assumptions can be made about the relative preferences for environmental functions and produced goods.

One of the possible assumptions is that the economic agents, individuals and institutions, have a dominant preference for an environmentally sustainable development. This assumption is legitimate since governments and institutions all over the world have stated support for environmental sustainability. The environmentally sustainable income (eSNI), to be dealt which later, is based on this assumption. Another possible assumption is that the economy is currently on an optimal path that is described by the changes in the standard NI. So both the eSNI and the standard NI are fictitious in the context of what is at issue in economic theory and statistics, namely to provide indicators of the effect of our actions on our welfare.

When assuming dominant preferences for sustainability, the unknown demand curves must be replaced by physical standards for sustainable use of the physical environment. The standards are scientifically determined and in this sense objective. They must, of course, be distinguished clearly from the subjective preferences for whether or not they should be attained; they are not target setting. Examples are: the man-made rate of extinction of species should not exceed the rate at which new species come into being, for safeguarding the many functions of ecosystems; the emission of greenhouse gases has to be reduced by 70 to 80 percent in order to let life support systems restore the climate; the rate of erosion of topsoil may not exceed the rate of formation of such soil due to weathering, for safeguarding the function: „soil for raising crops“.

From an economic perspective, sustainability standards approximate demand curves that are vertical in the relevant area of a diagram that has the availability of functions measured in physical units on the x-axis and the demand for functions and their opportunity costs on the y-axis. The shadow price for environmental functions and their value based upon the assumed preferences for sustainability then follows from the intersection of the vertical line and the marginal cost-effectiveness curve. In this manner the distance to sustainability, denoted in physical units on the x-axis, is translated into monetary units. See Figure 1, taken from Hueting (1974/1980), which shows the relationship between economy and ecology. Of course, bridging the gap requires a transition period.

The greater the distance between the present economy and the desired more environmentally benign economy that has to be bridged, the higher the costs of the required set of elimination measures are, as Figure 1 shows. These measures, enumerated above, are interacting with deliveries of all products, including services. So, when bringing these measures into practice, the interdependences between the producers, consumers and the environment make all commodity flows and prices change. For a correct approximation, such calculations have to be done by a general equilibrium model, which also generates the shadow prices for produced goods in a sustainable economy. The level of sustainable national income follows from such a model as well.

\section{A national income ex asymmetric entries}

Producing is defined, in accordance with standard economic theory, as the adding of value. This value is added to the nonhuman-made physical surroundings. Consequently, environmental functions, the most fundamental economic goods at human's disposal, remain outside the measurement of standard NI. This is logical and easy to understand, because water, air, soil, plant and animal species and the life support systems of our planet are not produced by humans. So losses of functions, caused by production and consumption, are correctly not entered as costs. However, expenditures on measures for their restoration and compensation are entered as value added. This is asymmetric. These expenditures should be entered as intermediate, as they are costs.

This asymmetry is often defended by the remark that these expenditures contribute to welfare and generate income. This is of course self-evident, counting from the moment at which the loss of environmental functions and the consequential adverse effects have already occurred. However, the production factors, used for the measures, do not add any value counting from the moment that the functions were still available. With respect to that situation there is consequently no increase in firstly, the quantity of final goods produced and secondly, the availability of environmental functions. Opposite to the income earned with carrying into effect the measures there stays consequently no increase in production volume, the final goods produced, with respect to that situation. Moreover loss and repair of functions often occur in the same year. By entering these expenditures as 
final instead of intermediate, that is as costs, the growth of production is overestimated, thus obscuring what is happening with both environment and production.

An NI ex asyms, apart from being useful in itself, is also important for the environmentally sustainable national income (eSNI) dealt with in below. The eSNI is above all intended for gauging the distance between the achieved and the sustainable level of production in the course of time. Because expenditure on a number of elimination measures and a great deal of expenditure on repairing damage and on compensation measures are booked as contributions to the NI, NI is not a good yardstick of the development of the level of production. During a transition to the sustainable path the distance between NI and eSNI may increase as a result. While at the same time the gap between the sustainable and the present level of production, the NI ex asyms, which is what it is all about, decreases. Hence the gap that has to be bridged to achieve a sustainable level of production is NI ex asyms minus eSNI and not NI minus eSNI. The formal mathematical details are outlined in de Boer and Hueting (2010).

\section{Environmentally Sustainable National Income}

Environmentally sustainable national income (eSNI) is defined as the maximal attainable production level by which vital environmental functions remain available for future generations, based on the technology available at the time. Thus the eSNI provides information about the distance between the current and a sustainable situation. In combination with the standard national income (NI), the eSNI indicates whether or not the part of the production that is not based on sustainable use of the environment, is becoming smaller or greater. Because of the precautionary principle, future technological progress is not anticipated in the calculation of eSNI. When constructing a time series of eSNI's, technological progress is measured after the event on the basis of the development of the distance between the eSNI and standard NI over the course of time. When this distance increases, society is drifting farther away from environmental sustainability, if this distance decreases, society is approaching environmental sustainability. The eSNI is based on the assumption of preferences for environmental sustainability, on physical sustainability standards and on the logical condition that the measures to attain sustainability, enumerated above, are taken simultaneously in all countries.

The theory of and the necessary statistics for an eSNI have been worked on since the mid sixties. A first rough estimate of the eSNI for the world by Tinbergen and Hueting arrives at roughly fifty percent of the production level of the world: the world income (Tinbergen/Hueting 1991). Estimates for The Netherlands also arrive at about fifty percent of the production level or national income of The Netherlands (Verbruggen et al. 2001; Hueting/de Boer 2001). In the period 1990 to 2005 the distance between NI and eSNI increased by thirteen billion euro or 10 percent.

The necessary condition for sustainability is that environmental functions are maintained for future generations, at the lowest levels of availability that enables the physical elements of the environment, which are the carriers of the functions, to remain supporting these levels. This is the case when the sustainability standards are met. The data of the cost of the meas- $\rightarrow$

Figure 1: Translation of costs in physical units into costs in monetary units

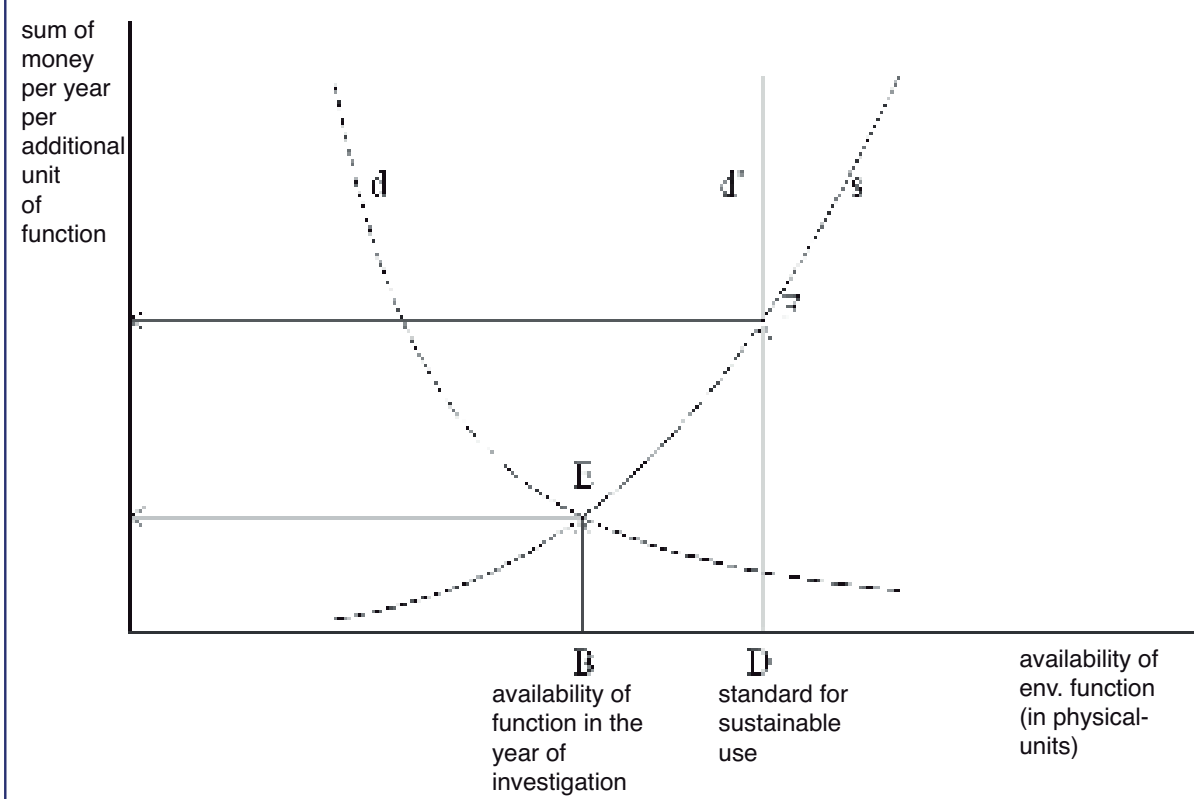

$\mathrm{s}=$ supply curve or marginal elimination cost curve;

$\mathrm{d}=$ =incomplete demand curve or marginal benefit curve based on individual preferences revealed from expenditures on compensation of functions, and so on;

d' = 'demand curve' based on assumed preferences for sustainability;

$\mathrm{BD}=$ distance that must be bridged in order to arrive at sustainable use of environmental functions;

area $\mathrm{BEFD=total}$ costs of the loss functions, expressed in money; the arrows indicate the way in which the loss of environmental functions recorded in physical units is translated into monetary units. The availability of the function (B) does not need to coincide with the level following from intersection point $(E)$.

Source: Hueting 1974/1980 
ures to attain the standards and thus maintain vital functions are estimated in the way just now discussed. An approximation of the eSNI is obtained with the aid of an economic model (Verbruggen et al. 2001; Hueting/de Boer 2001).

The model traces the consequences of firstly, the reactions to the change in price ratios (environment burdening activities become relatively more expensive, whereas environmentally benign activities become relatively cheaper) and secondly, direct shifts to environmentally less burdening activities.

The change in price ratios can be elucidated as follows. It follows from research in the basic source material of the Dutch national accounts that the bulk of national income growth is generated by industries that cause the greatest losses of environmental functions, both in production and in consumption. The increase in productivity in these industries, measured in terms of goods produced, is much greater than elsewhere in the economy, so the real prices of these products decrease strongly, and, with them, the price ratio between environmentally burdening and less burdening products. When, as in the simulation of environmentally sustainable income, the cost for attaining environmental sustainability are internalised in the prices of environment burdening products, the real prices of the latter increase, as does the price ratio between environmentally burdening and friendly products. The latter price ratios reflect the situation in an environmentally sustainable situation. Attaining environmental sustainability without a drastic change in price ratios is infeasible. Internalising the sustainability costs step by step, in order to finance environmental measures, can only be realised be levies imposed by the governments. The market is not able to realise this.

\section{The fallacy of the production must grow}

The political statement that the production must grow to finance safeguarding the environment, is a common fallacy. There are six arguments to show the fallacy of this statement (Hueting/Reijnders 2004). I shall mention two of them.

Firstly, the combination of production growth and safeguarding environmental functions would require technologies that simultaneously: (i) are sufficiently clean, (ii) do not deplete renewable natural resources, (iii) find substitutes for non-renewable resources, (iv) leave the soil intact, (v) leave sufficient space for the survival of plant and animal species and (vi) are cheaper in real terms than current available technologies, because if they are more expensive in real terms then growth will be reduced. Meeting all these six conditions is scarcely conceivable for the whole spectrum of human activities. Especially simultaneously realising both (i) through (v) and (vi), which is a prerequisite for combining production growth and conservation of the environment, is extremely difficult. Anyhow, technologies necessary for the combination of production growth and full conservation of the functions of the environment are not yet available. Anticipating the future availability of such technologies conflicts with the precautionary principle, and consequently with sustainabil- ity, which is, of course, certainly not the same as forecasting or not expecting technological progress.

Secondly, an analysis of the basic source material of the Dutch national accounts shows that roughly one third of the activities making up standard NI, measured as labour volume, do not contribute to its growth. These activities include governance, the administration of justice and most cultural activities. Part of the services sector contributes moderately to the growth of NI, while the remaining one third contributes by far the largest part to the growth of production. Unfortunately, this latter third consists of activities associated with production and consumption that cause the greatest damage to the environment in terms of loss of nature and biodiversity by use and fragmentation of space, pollution and depletion of resources. These activities include the oil and petrochemical industries, agriculture, public utilities, road construction and mining. These results are almost certainly valid for other industrialised countries and probably valid for developing countries (Hueting 1981; Hueting et al. 1992).

\section{The fallacy of a conflict between environment and employment}

The main stumbling block on the way to environmental sustainability is the alleged conflict between environment and employment. However, environmental functions are scarce goods that require the use of production factors for their restoration, preservation and substitution. Of these, labour is the most important. In the Netherlands, more than 80 percent of net Domestic Product is labour income. Capital goods are manufactured by labour, using elements of our physical surrounding. The production and consumption of the same amount of goods requires more labour with safeguarding the environment than is required without. In Hueting (1996) it is shown that with direct shifts to environmentally benign activities, attaining a certain goal requires more labour. Therefore, there is, under logical conditions, no such conflict. On the contrary, the opposite holds true. These logical conditions are firstly, income has to be reduced in proportion to the costs of the measures required to conserve the environment and secondly, these or similar measures must be taken to the same degree simultaneously by other firms involved, in all countries.

\section{The fallacy that saving the environment is unpayable}

A widespread fallacy about the environmental problem is: „We would like to save the environment, but alas, it is too expensive". However, the contrary holds true: all fundamental solutions for safeguarding the environment are clearly much cheaper than continuing the process that is threatening life on this planet.

One example is that travelling by bicycle is much cheaper than driving the same distance by car. Heating one room, in 
combination with a sweater and an extra blanket, is much cheaper than heating the entire house. A vacation by boat or train is cheaper than a holiday flight. A diet combining some meat and beans is cheaper than eating lots of meat. Winter vegetables in winter are cheaper than summer vegetables in winter. Raising two children is cheaper than raising ten.

Of course there is an economic sacrifice to be made. Otherwise there would be no environmental problem. Most of us would love to make unrestricted use of the private car, are mad about eating meat, and prefer to have sex without a pill or condom. However, the shift to environmental sustainability comes down to adapting the number of individuals of our species and the kind of activities we engage in to the carrying capacity of our planet, and this adaptation is extraordinarily cheap.

\section{Conclusion and recommendation}

The arguments given above lead to the following conclusion and recommendation. Firstly, our planet is threatened by a wrong belief in a wrongly formulated growth. And secondly, the National incomes or gross domestic products in all countries should be supplemented by a series of National incomes without asyms and a series of Environmentally sustainable national income, alongside the standard National income, in order to improve the information.

\section{References}

de Boer, B. / Hueting, R.: Relative NI ex asyms en mDNI. Internet: www.sni-hueting.info, 2010.

Goodland, R.: The concept of environmental sustainability. In: Aun. Rev. Ecol. Syst. 26/1995, S.1-24.

Hueting, R.: New Scarcity and Economic Growth: More Welfare Through Less Production?, Dutch edition: Agon Elsevier, Amsterdam 1974. English edition: North-Holland Publishing Company, Amsterdam, New York, 1980
Hueting, R.: Correcting National Income for Environmental Losses: Toward a Practical Solution. In: Ahmad, Y.J. et al. (Eds.): Environmental Accounting for Sustainable Development. UNEP World Bank 1989.

Hueting, R.: Three Persistent Myths in the Environmental Debate. In: Ecological Economics 18, 27 1996, S. 81-88.

Hueting, R. / Bosch, P. / de Boer, B.: Methodology for the Calculation of Sustainable National Income, Statistical Essays, CBS Statistics Netherlands, s-Gravenhage. Also published as WWF International report, Gland 1992.

Hueting, R. / Reijnders, L.: Broad Sustainability contra Sustainability: The Proper Construction of Sustainability Indicators. In: Ecological Economics 50, 3-4/2004, S. 249-260.

Hueting, R. / de Boer, B.: Environmental Valuation and Sustainable National Income According to Hueting. In: van lerland, E. C. et al.(Eds.): Economic Growth and Valuation of the Environment: A Debate. Edward Elgar, London 2001. S. 17-77.

Reijnders, L.: Environmentally Improved Production Processes and Products, Kluwer Scientific Publishers. Dordtrecht 1996.

Tinbergen, J. / Hueting, R.: GNP and Market Prices: Wrong Signals that Mask Environmental Destruction. In: Goodland, R. et al. (Eds.): Environmental Sustainable Economic Development: Building on Brundtland, UNESCO, Paris 1991. S. 51-57.

Verbruggen, H. / Dellink, R.B. / Gerlach, R. / Hofkes, M.W./ Jansen, H.M.A.: Alternative Calculations of a Sustainable National Income for the Netherlands According to Hueting. In: van lerland, E.C. et al (Eds.): Economic Growth and Valuation of the Environment: A Debate. Edward Elgar, London 2001. S. 275-312.

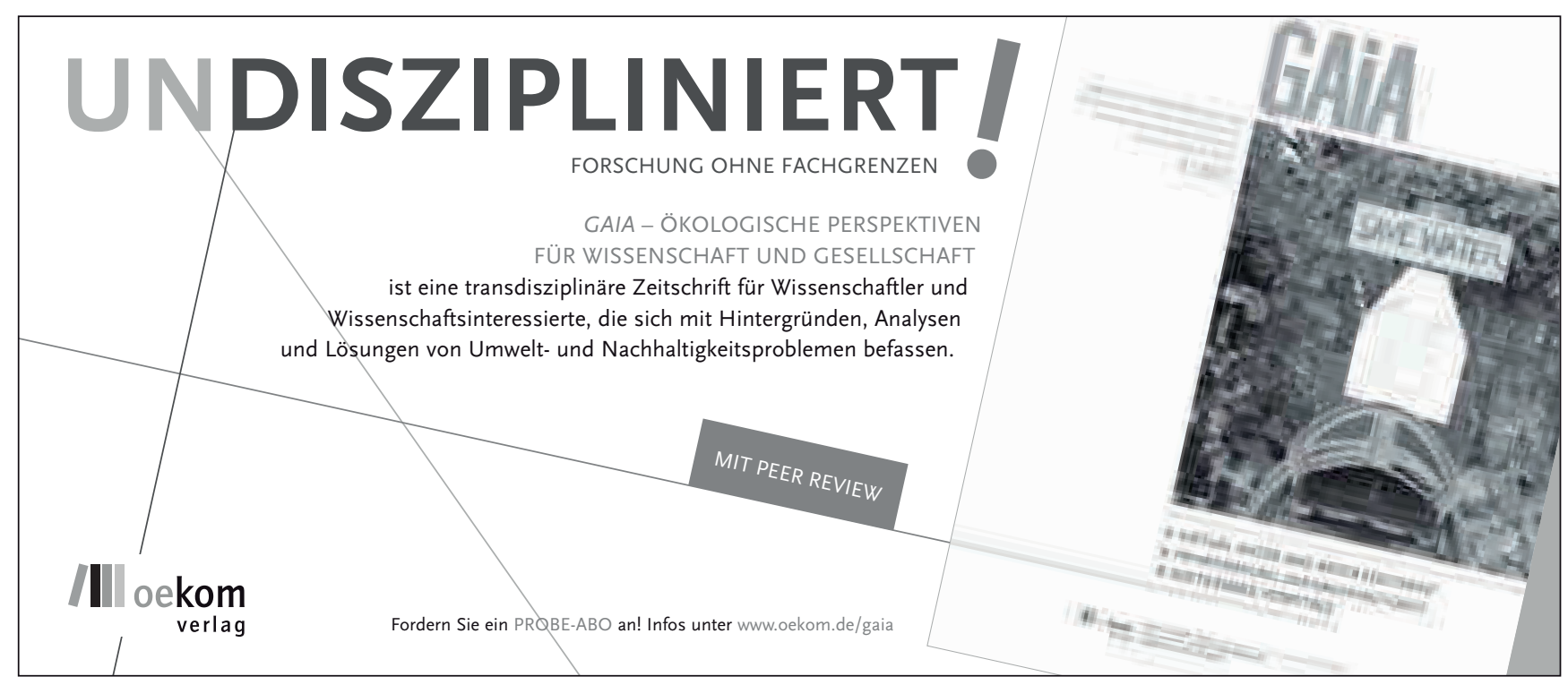




\section{Lizenzhinweis}

Die Beiträge in ÖkologischesWirtschaften werden unter der Creative-Commons-Lizenz "CC 4.0 Attribution Non-Commercial No Derivatives" veröffentlicht. Im Rahmen dieser Lizenz muss der Autor/Urheber stets genannt werden, das Werk darf nicht bearbeitet, abgewandelt oder in anderer Weise verändert und außerdem nicht kommerziell genutzt werden. Die digitale Version des Artikels bleibt für zwei Jahre Abonnent/innen vorbehalten und ist danach im Open Access verfügbar. 